\title{
KARL MARX: Educação Tecnológica/ Politécnica e a atualidade das suas reflexões
}

\begin{abstract}
ANTHONE MATEUS MAGALHÃES AFONSO
Instituto Federal Fluminense. Professor do Ensino Básico, Técnico e Tecnológico do IF Fluminense. Doutor em Educação. Mestre em Engenharia Mecânica - Controle e Automação, Pós-Graduação Lato Sensu em Informática na Educação e em Administração de Sistemas de Informação e Graduação em Informática. Líder do Núcleo de Pesquisas em Telecomunicações (NPT) do IF Fluminense. ORCID: 0000-0002-3897-1561. E-mail: anthone.mateus@gmail.com

\section{WANIA REGINA COUTINHO GONZALEZ}

Universidade do Estado do Rio de Janeiro. Doutora em Educação. Professora do Programa de Pós-Graduação em Educação da Universidade Estácio de Sá; Professora Adjunta da Universidade do Estado do Rio de Janeiro - Faculdade de Educação da Baixada Fluminense, Rio de Janeiro-RJ, Brasil. Líder do Núcleo de Pesquisa Políticas Públicas e Gestão da Universidade Estácio de Sá. ORCID: 0000-0002-4803-909X. E-mail: waniagonzalez@gmail.com
\end{abstract}




\section{KARL MARX: Educação Tecnológica/Politécnica e a atualidade das suas reflexões}

O objetivo principal deste artigo é analisar e discutir a concepção de educação tecnológica/politécnica formulada no século XIX por Karl Marx, considerando sua historicidade. Foi realizada pesquisa documental para identificar os principais textos que tratavam de suas propostas educacionais e consideradas as contribuições de renomados comentadores de suas obras. Não se pretende esgotar as discussões sobre essas propostas, mas levantar aspectos fundamentais delas para o desenvolvimento da Educação Profissional e Tecnológica (EPT) na atualidade. A partir do estudo empreendido e das análises efetuadas considerando o contexto histórico de sua formulação, verificam-se propostas educacionais voltadas para uma formação mais ampla, humana, onilateral, que contempla a articulação entre teoria e prática, trabalho técnico intelectual e trabalho técnico manual, uma formação não voltada apenas para as especificidades e particularidades das funções ocupacionais nas indústrias ou empresas, sob os interesses do capital: algo tão importante e ainda atual mesmo no século XXI, onde verificamos, por exemplo, a implantação da Reforma do Ensino Médio indo de encontro à perspectiva da onilateralidade.

Palavras chave: Concepção de educação. Educação profissional e tecnológica. Trabalho e educação.

\section{KARL MARX: Technological / Polytechnic Education and the currentity of his reflections}

The main objective of this paper is to analyze and discuss the conception of technological / polytechnic education formulated in the nineteenth century by Karl Marx, considering its historicity. Documentary research was conducted to identify the main texts that dealt with his educational proposals and considered the contributions of renowned commentators of his works. It is not intended to exhaust the discussions on these proposals, but to disclose fundamental aspects of them for the development of Professional and Technological Education (EPT) today. From the elaborate study and the analyzes made considering the historical context of its formulation, there are educational proposals that seek a broader, human, onilateral teaching, which contemplates the articulation between theory and practice, intellectual technical work and manual technical work, a formation not only focused on the specificities and particularities of occupational functions in industries or companies, under the interests of capital: something so important and still present even in the 21st century, where we verify, for example, the implementation of the Middle School Reform going against the perspective of onilaterality.

Keywords: Conception of education. Professional and technological education. Work and education.

\section{KARL MARX: Educación Tecnológica / Politécnica y la actualidad de sus reflexiones}

El objetivo principal de este artículo es analizar y discutir la concepción de la educación tecnológica / politécnica formulada en el siglo XIX por Karl Marx, considerando su historicidad. Se realizó una investigación documental para identificar los principales textos que trataban sus propuestas educativas y se consideraron las contribuciones de reconocidos comentaristas de sus obras. No se pretende agotar las discusiones sobre estas propuestas, sino plantear aspectos fundamentales de ellas para el desarrollo de la Educación Profesional y Tecnológica (EPT) en la actualidad. A partir del estudio realizado y los análisis realizados considerando el contexto histórico de su formulación, encontramos propuestas educativas dirigidas a una formación más amplia, humana y onilateral, que incluye la articulación entre teoría y práctica, trabajo técnico intelectual y trabajo técnico manual, una formación no solo centrada en las especificidades y particularidades de las funciones ocupacionales en industrias o empresas, bajo los intereses del capital: algo tan importante y todavía presente incluso en el siglo XXI, donde verificamos, por ejemplo, la implementación de la Reforma de la Escuela Secundaria contra desde la perspectiva de la onilateralidad.

Palabras clave: Concepción de la educación. Educación profesional y tecnológica. Trabajo y educación.

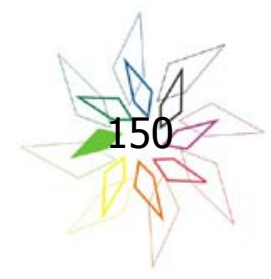




\section{KARL MARX: Educação Tecnológica/Politécnica e a atualidade das suas reflexões}

\section{Introdução}

A Educação Profissional e Tecnológica (EPT), abrangendo desde a formação inicial e continuada, passando pela educação profissional técnica de nível médio e chegando até a educação profissional tecnológica de graduação e pós-graduação, conforme previsto no parágrafo $2^{\circ}$ do artigo 39 da LDB - Lei n. 9.394/1996, revela, ao longo da história da educação brasileira, a adoção de diferentes concepções de educação.

Essas diferentes concepções são materializadas em programas de governo, regulamentos, leis e decretos, políticas públicas, dentre outros instrumentos responsáveis por definir, normatizar e orientar a oferta e o desenvolvimento das ações de EPT no Brasil, o que inclui a organização e reorganização da rede federal de educação profissional e tecnológica em diferentes momentos de acordo com o modelo adotado.

Ao tratar das concepções de educação na EPT, assim como em outros segmentos da educação, o contexto histórico é fundamental para a análise dos modelos adotados/implantados. Não se observa ao longo da história do Brasil uma uniformidade de oferta e de programas de educação profissional sob a égide de uma única concepção. Pelo contrário, percebem-se alternâncias entre diferentes modelos, com diferentes concepções, formando uma espécie de "zigue-zague", revelando descontinuidades e mudanças de percurso com alternância ou acomodação de diferentes formatos. Tais alternâncias estão geralmente relacionadas a mudanças de governos, crises estruturais nacionais e/ou internacionais, e se materializam a partir de propostas individuais ou de organizações nacionais e internacionais de vários setores.

Para Cattani (1997), a formação profissional pode ser feita através de duas modalidades. Na primeira, mais conhecida e difundida, considera apenas a sua dimensão restrita, operacional, de preparação para o trabalho. A formação profissional "aparece como um subproduto do sistema educacional ou como um componente das estratégias empresariais no que concerne à adequação dos recursos humanos às necessidades pontuais e específicas" (CATTANI, 1997, p. 98). Ela surge como um antídoto para o desemprego, sustentando que se os trabalhadores tivessem mais formação técnica haveria emprego para todos. 
Na segunda perspectiva, a formação profissional adquire um status teórico mais relevante, integrando o "complexo debate sobre a relação Educação-Trabalho, que implica, de um lado, o questionamento sobre o papel condicionador da escola e sua produtividade ou improdutividade" e de outro "a questão do trabalho como princípio educativo e libertador ou como fator de alienação e domesticação à lógica produtivista" (CATTANI, 1997, p. 99).

Esse embate de propostas entre uma educação mais rápida voltada para o mercado de trabalho ou mais ampla, visando uma formação integral para além dele, percorre toda a história da educação e acumula importantes defesas, propostas e teorias de diferentes estudiosos e pesquisadores até os dias atuais. Nesse universo de propostas voltadas para uma formação mais ampla do trabalhador, uma formação integral, encontram-se as formuladas por Karl Marx, no século XIX, e por Antonio Gramsci, no século XX, que apresentam grande recorrência nas pesquisas educacionais no campo da educação profissional.

No recorte delimitado para este trabalho serão apresentadas e discutidas as propostas de educação formuladas por Karl Marx, no século XIX, considerando o momento histórico em que foram formuladas e a atualidade e aplicabilidade nos tempos atuais, em pleno século XXI.

Ao longo da exposição e discussão dessas propostas serão apresentados também em contrapartida aspectos da formação mais rápida, voltada para atuação imediata no mercado de trabalho.

Segundo Moura (2013, p. 146-147), Marx propõe uma educação intelectual, física e tecnológica, sinalizando para a formação integral do ser humano, abrangendo todas as dimensões da vida, ou seja, onilateral. "Essa concepção de formação humana foi incorporada à tradição marxiana $^{1}$ sob a denominação de politecnia ou educação politécnica, em função das próprias referências do autor ao termo, assim como da maioria dos estudiosos de sua obra".

Sobre o melhor termo para representar a concepção educacional de Marx, Moura (2013, p. 146) esclarece:

É amplamente conhecida a polêmica sobre se o termo é politecnia/educação politécnica ou se é educação tecnológica o que melhor representa a concepção educacional de Marx. Enquanto a maioria dos autores assume que politecnia/ educação politécnica é o que representa o pensamento marxiano/marxista, há importantes estudiosos, como, por exemplo, Mário Manacorda e Paolo Nosella, que criticam o uso desse termo como sendo representativo da

\footnotetext{
${ }^{1}$ Marxiana no sentido de referência às ideias do próprio Marx.
} 
concepção educacional de Marx. Por outro lado, Saviani (2003b) compreende que os termos são equivalentes.

Neste artigo privilegiaremos a discussão sobre a potencialidade que a sua proposta educacional possibilita para a formação humana sem particularizar as polêmicas que a questão da terminologia suscitou.

\section{Compreendendo o momento histórico de desenvolvimento das propostas educacionais de Marx}

Antes de apresentar e discutir a proposta educacional de Marx e, em grande parte, de autoria com Engels, faz-se importante uma contextualização histórica do momento em que surgiram essas propostas.

Sua produção intelectual se deu no século XIX e sofreu grande influência da chamada "Primeira Revolução Industrial" que ocorreu na Inglaterra no final do século XVIII, com a utilização da máquina a vapor, do coque, impulsão da indústria têxtil, construção das primeiras ferrovias, etc. (NOGUEIRA, 1990).

Também é perceptível em suas obras e propostas educacionais, a preocupação com um problema social advindo das fábricas nascentes: a utilização de crianças para a operação das novas máquinas nas indústrias.

Não temos a pretensão de afirmar que apenas esses dois fatores (apesar deles não serem diminutos o suficiente para associação ao advérbio "apenas") influenciaram os trabalhos e concepções de Marx e Engels, mas é fortemente perceptível a presença em suas obras, conforme será apresentado adiante nos textos que trazem os indicativos de suas propostas educacionais.

A Revolução Industrial trouxe uma série de inovações técnicas que marcaram a transição da produção tradicional de caráter artesanal para a produção industrial moderna. "O modo de trabalho baseado principalmente na habilidade e destreza humanas é substituído por uma nova forma de produzir que se assenta sobre o sistema de máquinas" (NOGUEIRA, 1990, p. 24). Surgia um novo sistema onde as tradicionais fontes de energia (humana e animal) eram substituídas por novas formas, como a energia hidráulica e a vapor, aumentando a produtividade e garantindo maior rapidez, precisão e regularidade. 
Esse novo maquinismo acarretou em uma grande deterioração das condições de trabalho, seja na extensão da jornada e da intensificação do ritmo de trabalho, seja na redução dos salários ou na utilização selvagem da força de trabalho de mulheres e crianças (NOGUEIRA, 1990). Essa mesma industrialização também tornou possível o emprego de mulheres e crianças na produção, conforme bem percebeu Marx quando destacou o impacto da indústria mecanizada sobre o destino dos trabalhadores:

À medida que a maquinaria torna a força muscular dispensável, ela se torna o meio de utilizar trabalhadores sem força muscular ou com desenvolvimento corporal imaturo, mas com membros de maior flexibilidade. Por isso o trabalho de mulheres e de crianças foi a primeira palavra-de-ordem da aplicação capitalista da maquinaria! Com isso, esse poderoso meio de substituir trabalho e trabalhadores transformou-se rapidamente num meio de aumentar o número de assalariados, colocando todos os membros da família dos trabalhadores, sem distinção de sexo nem idade, sob o comando imediato do capital. (MARX, 1996, t.2, p.28).

O trabalho infantil não teve início com a Revolução Industrial, como bem ressalta Nogueira (1990). Em épocas anteriores já se utilizava as crianças de outras formas, como nas atividades rurais junto à família para capinar o terreno, revolver o feno ou guiar o rebanho; ou na oficina do artesão como aprendiz ao lado do oficial. Porém, a indústria que surgiu com essa revolução foi responsável por uma grande transformação: "a difusão em larga escala do trabalho infantil e, sobretudo, as penosas condições em que ele passa a se dar" (NOGUEIRA, 1990, p. 25).

Mas, quais as razões da difusão do emprego das crianças nas fábricas? Marx e Engels apontam em seus textos algumas delas. Uma primeira seria a mutação nas técnicas de fabricação que tornaram a força muscular dispensável, conforme passagem de O Capital citada acima. Outra razão seria a estratégia dos fabricantes de diminuir seus gastos com a força de trabalho, uma vez que as crianças recebiam salários baixíssimos, chegando a metade ou um terço do salário de um operário. Segundo Engels (2010, p. 175-176),

Diante de tudo isso, a burguesia argumenta que os aperfeiçoamentos introduzidos nas máquinas, que reduzem os custos de produção, permitem oferecer as mercadorias a preço mais baixo e que um tal preço provoca o aumento do consumo a um nível que propicia aos trabalhadores desempregados logo reencontrar trabalho nas novas fábricas que se abrem. Não há dúvida de que a burguesia tem plena razão quando afirma que, em certas condições favoráveis ao desenvolvimento industrial, toda redução do preço das mercadorias, cuja matéria-prima custe pouco, faz crescer o consumo e estimula a abertura de 
novas fábricas; mas, quanto ao resto, todas as suas palavras não passam de mentiras. Ela finge ignorar que, para que as consequências da redução dos preços se façam sentir, é preciso esperar anos até que as novas fábricas sejam construídas. Nada diz sobre o fato de os aperfeiçoamentos mecânicos, deslocando cada vez mais para as máquinas o trabalho que exige esforços, transformarem o trabalho de homens adultos em simples vigilância, que pode ser executada por uma mulher frágil ou mesmo por uma criança, o que eles efetivamente fazem pela metade ou por um terço do salário de um operário - ou seja, a burguesia esconde o fato de que os homens adultos são cada vez mais afastados da indústria e não são novamente ocupados com o aumento da produção industrial. Também dissimula o fato de ramos inteiros da indústria desaparecerem ou se modificarem a tal ponto que passam a exigir uma nova aprendizagem. Trata de ocultar aqui o aspecto de que tanto se gaba quando é discutida a proibição do trabalho infantil, ou seja, que o trabalho fabril, para ser bem executado, deve ser aprendido na primeira infância e antes dos dez anos (cf., por exemplo, Factories Inquiry Commission Report, passim). Nunca menciona que o aperfeiçoamento das máquinas se opera continuamente e que, se o operário consegue inserir-se num novo setor de trabalho (supondo que isso seja possível), logo será deslocado, perdendo, consequentemente, aquele pouco de segurança que ainda lhe restava para ganhar o pão.

Essa remuneração mais baixa das crianças permitia ainda que a classe capitalista forçasse para baixo o salário dos adultos, devido ao surgimento da concorrência provocada pela oferta dessa mão de obra infantil e com isso também a necessidade dos pais fazerem trabalhar seus filhos para contribuir com a renda familiar que estava mais baixa por causa dessa concorrência (NOGUEIRA, 1990). Verifica-se nesse prisma, um ciclo de desvalorização da mão de obra e um aumento da quantidade de trabalho à disposição do capital, não melhorando a situação financeira das famílias operárias como bem observou Marx:

O valor da força de trabalho era determinado pelo tempo de trabalho não só necessário para a manutenção do trabalhador individual adulto, mas para a manutenção da família do trabalhador. A maquinaria, ao lançar todos os membros da família do trabalhador no mercado de trabalho, reparte o valor da força de trabalho do homem por toda sua família. Ela desvaloriza, portanto, sua força de trabalho. A compra de uma família parcelada, por exemplo, em 4 forças de trabalho, custa, talvez, mais do que anteriormente a compra da força de trabalho do cabeça da família, mas, em compensação, surgem 4 jornadas de trabalho no lugar de uma, e o preço delas cai proporcionalmente ao excedente de mais-trabalho dos quatro em relação ao mais-trabalho de um. Agora, quatro precisam fornecer não só trabalho, mas mais-trabalho para 
o capital, para que uma família possa viver. Assim, a maquinaria desde o início amplia o material humano de exploração, o campo propriamente de exploração do capital, assim como ao mesmo tempo o grau de exploração (MARX, 1996, t.2, p.28-29).

E em outro momento da mesma obra, Marx ainda afirma: "O trabalhador vendia anteriormente sua própria força de trabalho, da qual dispunha como pessoa formalmente livre. Agora vende mulher e filho. Torna-se mercador de escravos" (MARX, 1996, t.2, p.29).

A semelhança desse trabalho ao de escravos evidenciava-se, por exemplo, na cessão ou negociação de órfãos e abandonados dos hospícios para atuação na indústria em troca apenas de abrigo e comida. Com a insuficiência desse plantel de mão de obra gratuita e os baixos salários percebidos, é que os pais começavam a se ver obrigados a também levar seus filhos para o trabalho como forma de aumentar a renda familiar, tão escassa devido aos baixos salários pagos conforme apresentado anteriormente. Era comum então encontrar crianças que trabalhavam nas mesmas indústrias que seus pais, geralmente até na mesma máquina como ajudantes. E esse trabalho se dava por longos períodos e, quase sempre, negligenciava-se qualquer possibilidade de estudo para essas crianças. Primeiro porque a educação básica naquela época era paga e, segundo, porque as crianças mal tintam tempo de estudar dada a alta jornada de trabalho.

Segundo Nogueira (1990), no século XIX, os governos dos diferentes países tentaram regulamentar o uso da mão de obra infantil em nome dos direitos da criança e a Inglaterra esteve à frente do processo com as leis chamadas de Factory Acts, imitadas posteriormente no continente. Essas leis regulamentadoras do trabalho infantil tratavam geralmente de três pontos principais:

De um lado, tratavam de regulamentar a idade mínima de admissão ao trabalho e a duração da jornada de trabalho; e, de outro, tentavam impor uma freqüência escolar mínima obrigatória para as crianças de fábrica, visando atenuar as suas carências em matéria de instrução (NOGUEIRA, 1990, p. 40-41).

$\mathrm{Na}$ Inglaterra, sucederam-se seis leis entre 1802 e 1844 para regulamentar as condições de trabalho dos menores (leis de 1802, 1819, 1825, 1831, 1833 e 1844). Concluindo essa série de seis leis votadas pelo Parlamento, a de 1844 regulamentou pela primeira vez na Revolução Industrial o trabalho do menor, uma vez que as leis posteriores - Factory Acts de 1847 e 1850 e Factory Act Extension de 1867 - tiveram por objetivo a redução da jornada de trabalho do adulto a menos de 12 horas, a extensão da legislação fabril aos outros setores industriais, a regulamentação das pequenas oficinas, dentre outros pontos (NOGUEIRA, 1990). Segundo Nogueira (1990, p. 49), a lei de 1844 tratava de: 
- implantar um regime de trabalho de meio período para as crianças com menos de 13 anos, as quais não poderiam mais trabalhar além de 6,30h por dia (em lugar das oito horas de antes); com isso pensava-se propiciar-lhes condições mais favoráveis de instrução;

- manter no patamar de 12 horas a jornada de trabalho dos adolescentes. Aqui a única novidade reside na equiparação das mulheres acima de 18 anos aos adolescentes; o que resultou, entre outras coisas, na proibição do trabalho noturno para elas e na limitação a 12 horas de sua jornada de trabalho. Isto, aliás, levará Marx, n'O Capital, a saudar nessa lei a primeira manifestação de controle sobre o trabalho adulto;

- diminuir para oito anos (em lugar de nove) a idade mínima de admissão ao trabalho. "Retrocesso" - dirá Marx - exigido pelos fabricantes para compensar os "progressos" mencionados acima;

- conferir aos inspetores de fábrica o direito de fiscalizar as escolas, notadamente para avaliar a competência dos mestres.

Apesar de alguns avanços, na prática, as crianças continuavam sem acesso à educação, e os inspetores de fábrica pouco faziam na verificação do cumprimento da exigência de frequência escolar obrigatória, negando o direito previsto de escolarização da mão de obra infantil.

A partir da obrigatoriedade determinada desde a lei de 1833, essas escolas destinadas às crianças operárias, quando existiam, eram de má qualidade, de tempo reduzido e abertas no próprio espaço da fábrica. Engels ao comentar os resultados dessa lei, afirma:

No que diz respeito à instrução obrigatória, ela praticamente não saiu do papel, porque o governo não providenciou a abertura de boas escolas; a instrução de que se encarregaram os industriais não teve melhor sorte: eles contrataram como professores operários inativos, com os quais as crianças passam duas horas diárias, cumprem formalmente a lei e nada aprendem (ENGELS, 2010, p. 209).

Os fabricantes geralmente contratavam pessoas sem qualificação para dar aulas às crianças, o que era compatível com a cláusula da lei que não exigia como prova de escolaridade mais do que um certificado expedido pelo mestre. Em alguns casos raros, eram abertas escolas no próprio espaço das fábricas para fornecer instrução aos pequenos trabalhadores (NOGUEIRA, 1990).

Continuavam as crianças executando os trabalhos menos qualificados - como ajudantes de adultos - e, sob o regime de fábrica, "extenuadas de tanto trabalhar, privadas de repouso e de ar 
livre, estropiadas, marcadas pelo resto da vida por graves deficiências e enfermidades" (NOGUEIRA, 1990, p. 69).

Não distante desse movimento de luta por condições mais justas para os trabalhadores adultos e crianças nas fábricas, é que Marx e Engels acenam para uma formação técnica, mas também intelectual para todas as crianças a partir de certa idade, combinando o ensino em todos os seus níveis com o trabalho produtivo.

Segundo Nogueira (1990) a expressão "trabalho produtivo" pode ter duas acepções diferentes em Marx. Em sua determinação geral, designa todo e qualquer trabalho que tenha por resultado um produto:

Considerando-se o processo inteiro de trabalho do ponto de vista de seu resultado, então aparecem ambos, meio e objeto de trabalho, como meios de produção, e o trabalho mesmo como trabalho produtivo (MARX, 1996, t.2, p.137)

Entretanto, essa expressão ganha outro sentido na produção capitalista, onde a finalidade é a obtenção de lucro e a lógica acumulação desse lucro. O sentido de trabalho capaz de produzir um excedente, o qual toma aí a forma de mais valia:

Por outro lado, porém, o conceito de trabalho produtivo se estreita. A produção capitalista não é apenas produção de mercadoria, é essencialmente produção de mais-valia. $\mathrm{O}$ trabalhador produz não para si, mas para o capital. Não basta, portanto, que produza em geral. Ele tem de produzir mais-valia. Apenas é produtivo o trabalhador que produz mais-valia para o capitalista ou serve à autovalorização do capital (MARX, 1996, t.2, p. 138).

Em síntese, "a primeira acepção, como se vê, diz respeito ao meio geral de reprodução da vida humana. A segunda, em contrapartida, traduz as condições específicas em que o trabalho se realiza sob a égide do capital" (NOGUEIRA, 1990, p. 90).

Concordando com Nogueira, é a primeira acepção que prevalece no modelo de educação defendido por Marx e Engels, onde se defende a coordenação dos estudos com o trabalho produtivo: eles empregam a expressão no seu sentido geral, no sentido de um trabalho que resulta na fabricação de valores de uso. Essa união (coordenação) deveria então contribuir para a extinção das condições capitalistas de exploração. Para Marx, "esta combinação do trabalho produtivo pago com a educação mental, os exercícios corporais e a aprendizagem politécnica, elevará a classe operária bem acima do nível das classes burguesa e aristocrática" (MARX, 1965, p. 1468 apud NOGUEIRA, 1990, p. 91)².

${ }^{2}$ MARX, K. Résolutions du premier congrès de 1'AIT. In Oeuvres 1. Paris, Gallimard, Bibliothéque de la Pléiade, 1965. 


\section{Educação Tecnológica/Politécnica em Marx}

De acordo com Manacorda (2007, p. 35), a partir de uma pesquisa filologicamente atenta às formulações explícitas e de uma perspectiva pedagógica nos textos de Marx e de Engels (que segundo ele são "absolutamente inseparáveis"), verifica-se a existência de textos explicitamente pedagógicos, mesmo que não sejam em grande número, com extraordinário relevo e com coerência, apesar da existência de uma distância de cerca de 30 anos entre eles. Dentre estes textos destacam-se as redações de três programas políticos:

a. Para o primeiro movimento histórico da revolução, que assumiu o nome de Partido Comunista, às vésperas da revolução de 1848;

b. Para a I Associação Internacional dos Trabalhadores, em 1866;

c. Para o Primeiro Partido Operário Unitário, na Alemanha, em 1875

O primeiro texto é Princípios do comunismo (primeira versão redigida em forma catequística por Engels em novembro de 1847) do que mais tarde viria a ser o Manifesto do partido comunista; e o texto definitivo deste manifesto, redigido por Marx no mês de janeiro de 1848 (MANACORDA, 2007).

No parágrafo 18 dos Princípios do Comunismo, Engels defende a instauração de uma constituição democrática que permitisse a adoção de medidas imediatas destinadas diretamente ao ataque da propriedade privada e a garantia da existência do proletariado (MANACORDA, 2007). A oitava dessas medidas seria:

Instrução a todas as crianças, assim que possam prescindir dos cuidados maternos, em institutos nacionais e a expensas da nação. Instrução e trabalho de fábrica [Fabrikation] vinculados (MARX; ENGELS, 1948c, p. 276-280 apud MANACORDA, 2007, p. 36) ${ }^{3}$.

Nessa defesa, Engels já apresenta duas propostas importantes: da gratuidade e da universalidade do ensino. E essa educação gratuita e universal deveria ainda unir instrução (ensino) e trabalho para todas as crianças, não só para os filhos dos proletários, uma vez que era defendida como universal. Segundo Manacorda (2007, p. 36), a união entre instrução e trabalho, nesse primeiro momento proposta por Engels, vinha sendo já proclamada e praticada por outros utópicos, "em especial por Robert Owen", mas este modelo de união seria posteriormente aperfeiçoado por Marx e alterado no Manifesto Comunista.

\footnotetext{
${ }^{3}$ MARX, K; ENGELS, F. Il manifesto del partido comunista. Tradução: Emma Cantimori Mezzomonti. Turim:
} Einaudi, 1948c. 
No mesmo documento, no parágrafo 20, respondendo à indagação sobre as consequências da abolição da propriedade privada, Engels afirma:

A divisão do trabalho, já mirada pela máquina, que transforma um em camponês, outro em sapateiro, outro em operário de fábrica, e ainda outro em especulador da bolsa, desaparecerá por completo.

O ensino permitirá aos jovens acompanhar o sistema total de produção, colocando-os em condições de se alternarem de um ramo da produção a outro, segundo os motivos postos pelas necessidades da sociedade ou por suas inclinações. Eliminará dos jovens aquele caráter unilateral imposto a todo indivíduo pela atual divisão do trabalho. Deste modo, a sociedade organizada pelo comunismo oferecerá aos seus membros a oportunidade de aplicar, de forma onilateral, atitudes desenvolvidas onilateralmente (MARX; ENGELS, 1948c, p. 276-80 apud MANACORDA, 2007, p. 37) .

E mais adiante, conclui:

O desenvolvimento onilateral das capacidades de todos os membros da sociedade, mediante a eliminação da divisão do trabalho até agora existente, mediante o ensino industrial (industrielle), mediante o alternar-se das atividades... (MARX; ENGELS, 1948c, p. 276-80 apud MANACORDA, 2007, p. 37) .

Alguns pontos destas passagens, no parágrafo 20, do documento preparado por Engels devem ser destacados: a união do ensino com trabalho produtivo ou Fabrikation, que prevê um estágio desenvolvido inteiramente no sistema de produção, procurando evitar a unilateralidade nos jovens, estimulando-lhes a onilateralidade, permitindo a alternância de sua atividade e satisfazendo desse modo tanto as exigências da sociedade como suas inclinações pessoais (MANACORDA, 2007); fica claramente exposta uma opção por um ensino que promova a visão ampla do sistema de produção, dando total entendimento de todo o processo aos jovens, contrastando com uma visão de ensino mais restrita e fragmentada, que prepara apenas para um posto de trabalho, sem a visão do todo. No entanto, apesar de prever uma formação onilateral em detrimento de uma preparação unilateral imposta pela divisão do trabalho, essa formação com objetivo de fazer com que os jovens possam se alternar de um ramo da produção a outro é rejeitada por Marx, conforme pode ser observado no trecho de uma das conferências que fez na União dos

\footnotetext{
${ }^{4}$ MARX, K; ENGELS, F. Il manifesto del partido comunista. Tradução: Emma Cantimori Mezzomonti. Turim: Einaudi, 1948c.

${ }^{5}$ Idem.
} 
Operários Alemãs, de Bruxelas (MARX; ENGELS, 1959b, p. 545 apud MANACORDA, 2007, p. 39)

Outra proposta preferida pelos burgueses é o ensino, em especial o ensino industrial [industrielle] universal...

$O$ verdadeiro significado que o ensino recebeu entre os economistas filantrópicos é este: treinar cada operário no maior número possível de ramos de trabalho, de modo que, se por introdução de novas máquinas ou por mudanças na divisão do trabalho, ele vier a ser expulso de um ofício, possa mais facilmente achar colocação em outro.

Pelo exposto, Marx discorda daquele ensino universal proposto inicialmente por Engels no parágrafo 20 , especificamente no que se refere ao que chamava de pluriprofissionalidade, o que fez com que não utilizasse esse parágrafo na redação do Manifesto (MARX; ANGELS, 1948b) e aproveitasse apenas os breves enunciados do parágrafo 18, citando como última medida imediata que o proletariado tomaria após o primeiro passo (após a conquista da democracia) (MANACORDA, 2007):

Ensino público e gratuito a todas as crianças. Abolição do trabalho das crianças nas fábricas em sua forma atual. Unificação do ensino com a produção material [mit der materiellen Produktion] (MARX; ENGELS, 1948b apud MANACORDA, 2007, p. 40) ${ }^{7}$.

Dessa passagem, verifica-se a semelhança com a defesa de um ensino gratuito e unido ao trabalho, como propunha Engels; e as diferenças por não definir que essa educação pública e gratuita fosse através de Institutos Nacionais, por não determinar a idade mínima para iniciar o ensino e também por não definir um ensino em certo momento apartado do trabalho e em outro a ele vinculado (MANACORDA, 2007). Existe ainda a importante defesa da abolição da então atual forma de trabalho das crianças nas fábricas, o que contrariava a proposta dos burgueses.

Marx e Engels entendem que a propriedade privada e a divisão do trabalho são causas da degradação do homem, observando entre outras coisas, que o operário, limitado a uma habilidade muito particular e impossibilitado de passar de uma ocupação a outra mais moderna, "somente

\footnotetext{
${ }^{6}$ MARX, K; ENGELS, F. Werke. Vol. II. Berlim: Dietz Verlag, $1959 \mathrm{~b}$.

${ }^{7}$ MARX, K; ENGELS, F. Manifesto del partido comunista. Piccola Biblioteca Marxista,Roma: Edizioni Rinascita, $1948 b$.
} 
pode viver se agregado a uma máquina particular num trabalho particular" (MARX; ENGELS, 1959a, p. 520 apud MANACORDA, 2007, p. 41) ${ }^{8}$.

Para Marx, a divisão do trabalho nada mais é que "'a expressão econômica da sociabilidade do trabalho na condição histórica da alienação humana', isto é, da propriedade privada" (MANACORDA, 2007, p. 41). E dessa condição do trabalho alienado, como fruto da divisão do trabalho, surge o homem unilateral. Mais tarde dirá que

[...] a verdadeira divisão do trabalho se apresenta como divisão entre trabalho intelectual e trabalho manual, e que, na fábrica mecanizada, o trabalho braçal perde todo caráter de especialização, mas que, no entanto, justamente quando cessa todo desenvolvimento especial, faz-se sentir também a tendência ao desenvolvimento onilateral do indivíduo (MANACORDA, 2007, p. 42).

E essa divisão do trabalho condiciona a divisão da sociedade em classes e a divisão do homem;

e como esta se torna verdadeiramente tal apenas quando se apresenta como divisão entre trabalho manual e trabalho mental, assim as duas dimensões do homem dividido, cada uma das quais unilateral, são essencialmente as do trabalhador manual, operário, e as do intelectual (MARX, 1952, p. 281 apud MANACORDA, 2007, p. 77) ${ }^{9}$.

Outro problema decorrente da divisão do trabalho e da alienação humana é a relação entre o tempo de trabalho e o tempo livre. Na definição marxiana que determina o sobre-trabalho como produtor de mais-valia, ou de capital, "institui-se uma relação entre o tempo de trabalho necessário (à vida e a reprodução do trabalhador) e aquele que aparece em princípio como um tempo disponível, que o capitalista tende a destinar, como sobre-trabalho, à produção de maisvalia" (MANACORDA, 2007, p. 69), negando a configuração de tempo livre para o próprio trabalhador.

Todas as possibilidades de vida plenamente humana, com liberdade, estão então ligadas ao problema do tempo de trabalho que o capitalista tende a prolongar em benefício próprio, e que também deve ser superado.

\footnotetext{
${ }^{8}$ MARX, K; ENGELS, F. Werke. Vol. I. Berlim: Dietz Verlag, 1959a.

${ }^{9}$ MARX, K. Manuscritos economico-filosofici de 1844. Roma: Edizioni Rinascita, 1952.
} 
Diante dessa realidade da alienação humana, na qual todo homem alienado por outro está alienado da própria natureza, está a exigência da onilateralidade defendida por Marx e Engels, com um "desenvolvimento total, completo, multilateral, em todos os sentidos, das faculdades e das forças produtivas, das necessidades e da capacidade da sua satisfação" (MANACORDA, 2007, p. 87).

Por isso a defesa de uma formação onilateral do homem em escolas com ensino tecnológico teórico e prático, superando a ruptura entre a ciência e o trabalho que ocorrera nas fábricas, contrariando a defesa de uma formação praticista e profissional que decorre do sistema capitalista (MANACORDA, 2007).

Retomando a ideia fundamental da união do ensino com o trabalho produtivo como parte do programa comunista (já publicado no Manifesto do Partido Comunista), cerca de 20 anos depois outro documento de grande importância $\left(2^{\circ}\right.$ texto de grande importância para a definição da concepção de educação em Marx, conforme mencionado anteriormente) foi publicado em setembro de 1866: as Instruções. Para Manacorda (2007), as Instruções entregues aos delegados do I Congresso da Associação Internacional dos Trabalhadores, em Genebra, são indissociáveis da elaboração contemporânea de O Capital. Numa clara definição da concepção de educação defendida, Marx afirma que:

Por ensino entendemos três coisas:

Primeira: ensino intelectual;

Segunda: educação física, dada nas escolas e através de exercícios militares;

Terceira: adestramento tecnológico, que transmita os fundamentos científicos gerais de todos os processos de produção e que, ao mesmo tempo, introduza a criança e o adolescente no uso prático e na capacidade de manejar os instrumentos elementares de todos os ofícios.

Com a divisão das crianças e dos adolescentes dos 9 aos 17 anos em três classes deveria estar vinculado um programa gradual e progressivo de ensino intelectual, físico e tecnológico...

A união do trabalho produtivo remunerado, ensino intelectual, exercício físico e adestramento politécnico elevará a classe operária acima das classes superiores e médias (MARX; ENGELS, 1962, p. 192 apud MANACORDA, 2007, p. 44) $)^{10}$.

${ }^{10}$ MARX, K.; ENGELS, F. Instruktionen fuer die delegierten des provisorischen zmtralrates zu den ein zelnen fragen. In: MARX, K; ENGELS, F. Werke. Vol. XVI. Berlim: Dietz Verlag, 1962. 
Em relação direta com o Manifesto, esse documento explicita melhor os elementos socialistas: abolição da então forma atual de trabalho das crianças na fábrica e união dos dois termos inseparáveis, ensino e trabalho produtivo (MANACORDA, 2007). Quanto ao ensino, destaca-se a associação do ensino intelectual, da educação física e do adestramento (treinamento) tecnológico. Fica claro nesta passagem que o ensino tecnológico não absorve nem substitui a formação intelectual e, ainda, que o ensino tecnológico aparece especificado com a indicação de seu aspecto teórico - mas que não substitui a formação intelectual - e prático, abrangendo onilateralmente os fundamentos de todos os processos de produção e os aspectos práticos de todos os ofícios - garantindo também uma visão sistêmica da produção. Mas deve-se destacar que essa visão do todo é centrada na libertação do homem da subordinação a um só ramo da produção, e não na pluriprofissionalidade para atendimento imediato às necessidades da indústria.

Nas páginas sobre ensino em O Capital, observa-se uma grande aproximação com a proposta de ensino contida nas Instruções (MANACORDA, 2007), mas deve-se cautelar que nesse fragmento apresentado a seguir, Marx se refere às escolas politécnicas como as historicamente existentes, e não no sentido da instrução ou treinamento politécnico que utilizou anteriormente como sendo essencial e capaz de modificar a relação de trabalho do operário.

Um momento, espontaneamente desenvolvido com base na grande indústria, desse processo de revolucionamento são as escolas politécnicas e agronômicas, outro são as écoles d'enseignement professionnel em que filhos de trabalhadores recebem alguma instrução de tecnologia e de manejo prático dos diferentes instrumentos de produção. Se a legislação fabril, como primeira concessão penosamente arrancada ao capital, só conjuga ensino elementar com trabalho fabril, não há dúvida de que a inevitável conquista do poder político pela classe operária há de conquistar também para o ensino teórico e prático da tecnologia seu lugar nas escolas dos trabalhadores (MARX, 1996, t.2, p.116).

Em outro texto programático sobre o ensino (o terceiro de grande importância para a definição da concepção de educação em Marx), as Notas à margem ao programa do partido operário alemão - mais conhecido como Crítica ao programa de Gotha - de 1875, Marx examina as formulações propostas pelo programa de unificação dos dois partidos operários alemães e comenta:

B) "O Partido Operário Alemão exige, como base espiritual e moral do Estado:"

P/Ulils Salvador, v. 4, n. 3, p. 149-169, set./dez. 2019 
1) Educação popular universal e igual sob incumbência do Estado. Escolarização universal obrigatória. Instrução gratuita.

Educação popular igual? O que se entende por essas palavras? Crê-se que na sociedade atual (e apenas ela está em questão aqui) a educação possa ser igual para todas as classes? Ou se exige que as classes altas também devam ser forçadamente reduzidas à módica educação da escola pública, a única compatível com as condições econômicas não só do trabalhador assalariado, mas também do camponês?

“Escolarização universal obrigatória. Instrução gratuita.” A primeira existe na Alemanha, a segunda na Suíça [e] nos Estados Unidos, para escolas públicas. Que em alguns estados deste último também sejam "gratuitas" as instituições de ensino"superior" significa apenas, na verdade, que nesses lugares os custos da educação das classes altas são cobertos pelo fundo geral dos impostos.[...]

O parágrafo sobre as escolas devia ao menos ter exigido escolas técnicas (teóricas e práticas) combinadas com a escola pública. [...]

"Proibição do trabalho infantil”! Aqui, era absolutamente necessário determinar o limite de idade. A proibição geral do trabalho infantil é incompatível com a existência da grande indústria e, por essa razão, um desejo vazio e piedoso. A aplicação dessa proibição - se fosse possível - seria reacionária, uma vez que, com uma rígida regulamentação da jornada de trabalho segundo as diferentes faixas etárias e as demais medidas preventivas para a proteção das crianças, a combinação de trabalho produtivo com instrução, desde tenra idade, é um dos mais poderosos meios de transformação da sociedade atual (MARX, 2012, p. 45 e 47).

Marx reforça então a necessidade de um vínculo precoce entre o ensino e o trabalho produtivo, desde a educação das crianças, mas condicionando à regulamentação severa da duração do trabalho delas nas várias idades, já que o trabalho infantil era amplamente explorado à época. Em 1866, tinha especificado a duração máxima de trabalho que defendia para cada idade, em um movimento de garantia de tempo livre para os filhos dos operários terem acesso à educação e transformarem a sociedade: "duas horas entre os 9 e 12 anos, quatro horas entre os 13 e 15 anos, seis horas entre os 16 e 17 anos" (MARX, ENGELS, 1962, p. 190"11; MARX, 1964 b, p. $82-83^{12}$ apud MANACORDA, 2007, p. 100).

\footnotetext{
${ }^{11}$ MARX, K.; ENGELS, F. Instruktionen fuer die delegierten des provisorischen zmtralrates zu den ein zelnen fragen. In: MARX, K; ENGELS, F. Werke. Vol. XVI. Berlim: Dietz Verlag, 1962.

${ }^{12}$ MARX, K. Il Capitale. Roma: Editori Riuniti, 1964b.
} 
As afirmações nesse documento de 1875 confirmam novamente os temas fundamentais da pedagogia marxiana: a união de ensino e trabalho produtivo para as crianças, desde que previamente abolido o que era chamado no Manifesto de "a sua forma atual"; e a exigência de escolas técnicas com conteúdo teórico e prático, o que constituiria a educação do futuro desejada por Marx nas Instruções e em O Capital (MANACORDA, 2007).

Sintetizando, mas não tentando acabar com as discussões sobre o princípio educativo em Marx, Manacorda (2007) faz dois apanhados interessantes sobre as teses de Marx voltadas para a educação.

Primeiro, ao expor de maneira esquemática o resultado da pesquisa marxiana sobre os temas de formação do homem:

[...] nada mais são que um aspecto dos temas da sua emancipação como indivíduo social, isto é, como ser singular inserido na sociedade de que participa - pode-se enunciá-lo como método da associação do trabalho em fábrica e de ensino numa escola essencialmente tecnológica, com a finalidade de criar o homem onilateral (MANACORDA, 2007, p. 117).

Segundo, ao confrontar o modelo educacional defendido por Marx e o modelo de "polivalência" ou "pluriprofissionalidade" a serviço do mercado, afirma sobre Marx:

[...] sua concepção do ensino tecnológico - "teórico e prático", como tinha esclarecido, em 1966, aos delegados do I Congresso da Internacional (Marx, 1962, p. 194) - exprime a exigência de fazer adquirir conhecimentos de fundo, isto é, as bases científicas e tecnológicas da produção e a capacidade de manejar os instrumentos essenciais das várias profissões, isto é, de trabalhar conforme a natureza - com o cérebro e as mãos, porque isso corresponde a uma plenitude do desenvolvimento humano. Em resumo, ao critério burguês da pluriprofissionalidade, Marx opõe a idéia da onilateralidade, do homem completo, que trabalha não apenas com as mãos, mas também com o cérebro e que, conscientes do processo que desenvolve, domina-o e não é por ele dominado. E parece que sua polêmica contra o que a burguesia entende por ensino técnico é atual ainda hoje, e, que, na moderna pedagogia socialista, há, por vezes, uma tendência de reduzir o politecnismo, ou melhor, o ensino tecnológico teórico e prático, a uma mera questão de disponibilidade, de pluriprofissionalidade (MANACORDA, 2007, p. 101).

Torna-se claro então o posicionamento e as propostas de Marx, em seu tempo (mas ainda tão atual em pleno século XXI), contra o ensino raso e imediatista para atendimento a uma 
atividade laboral específica; contra apenas o treinamento técnico para o desempenho de funções específicas requeridas pelas indústrias; contra a formação unilateral do homem; enfim, contra as propostas de uma formação imediata e barata que aliena o homem e maximiza os lucros da burguesia.

Esse pensamento continua vivo e faz parte do requerimento da sociedade, um pleito de vários educadores e pesquisadores da área de educação que defendem uma formação mais ampla, humana, onilateral, não voltada apenas para as especificidades e particularidades das funções ocupacionais nas indústrias ou empresas, sob os interesses do capital.

Nessa defesa, Saviani (1994) ao tratar do trabalho como princípio educativo frente as novas tecnologias, recupera o pensamento marxista para discutir a nova situação demandada pela Revolução da Informática ou Revolução da Automação. Para ele, se antes ocorreu uma transferência de funções manuais para as máquinas, o que hoje está ocorrendo é a transferência das próprias operações intelectuais para as máquinas.

Com isso as qualificações intelectuais específicas também tendem a desaparecer, o que traz como contrapartida a elevação do patamar de qualificação geral, atingindo o limiar da consumação do processo de constituição da escola como forma principal, dominante e generalizada de educação. E assim sendo, emerge novamente a necessidade de universalização de uma escola unitária que desenvolva ao máximo as potencialidades dos indivíduos (formação onilateral tal como defendida por Marx), deixando o terreno da utopia e da mera aspiração ideológica, moral ou romântica para se converter em uma exigência posta pelo próprio desenvolvimento do processo produtivo (SAVIANI, 1994).

Desponta então a necessidade de rediscussão, no campo do currículo, de como promover essa educação básica de qualidade para vencer os desafios da contemporaneidade, contemplando a articulação entre teoria e prática, trabalho técnico intelectual e trabalho técnico manual, a capacidade de manejar conceitos e o desenvolvimento do pensamento abstrato em tempos do trabalho de alta complexidade.

No cenário atual, onde se verifica uma "hipertrofia da escola" (SAVIANI, 1994), tanto no sentido vertical quanto no sentido horizontal, e dadas a complexidade e as exigências cada vez maiores do mundo trabalho, mostra-se contraditória a proposta de uma educação profissional desvinculada da educação básica, tal como proposto pela Reforma do Ensino Médio na Lei n. 13.415, de 16 de fevereiro de 2017. O que demonstra mais uma vez a atualidade do pensamento marxista diante da contradição que se insere na essência da sociedade capitalista: o trabalhador 
não pode ter meio de produção, não pode deter o saber; mas sem o saber ele também não pode produzir porque para transformar a matéria precisa dominar algum tipo de saber. Por isso é preciso saber, mas em doses homeopáticas, apenas o mínimo para operar a produção. Daí a escola entra nesse processo contraditório: ela é reivindicada pelas massas trabalhadoras, mas as camadas dominantes relutam em expandi-la (SAVIANI, 1994).

\section{Considerações finais}

Nas pesquisas sobre políticas públicas educacionais no escopo da EPT são frequentes as apropriações de conceitos e propostas formuladas por Marx. No entanto, algumas vezes verificam-se apropriações indevidas ou aproximações inadequadas pela falta de compreensão do momento histórico em que as propostas educacionais em tela foram formuladas. E foi justamente neste aspecto que este estudo propôs sua principal contribuição.

Em tempos de obscurantismo e falta de discussão de temas primordiais ao desenvolvimento de uma educação mais ampla e integral na agenda governamental, a partir da discussão dos principais conceitos e propostas para a educação profissional em uma pesquisa comprometida com a historicidade, verificou-se o quanto essas ideias eram modernas e avançadas em seu tempo, na defesa de uma educação mais ampla e humana, libertadora e onilateral, contemplando teoria e prática, trabalho técnico intelectual e manual, indo além da pluriprofissionalidade ou polivalência defendida pelo mercado em favor da precarização do trabalho. Uma defesa antiga, mas ainda tão atual, sobretudo com a aprovação da Reforma do Ensino Médio, Lei n. 13.415, de 16 de fevereiro de 2017, a partir da qual os jovens escolherão os seus itinerários formativos em um modelo de formação em tempo integral, mas não integrada ${ }^{13}$, se distanciando da tão cara e desejada formação onilateral.

\section{REFERÊNCIA}

AFONSO, A. M. M.; GONZALEZ, W. R. C. Desafios da Educação Profissional e Tecnológica: novas faces dos mesmos problemas. ComCiência (UNICAMP), Campinas, v. 203, p. 1-13, nov. 2018. Disponível em: < http://www.comciencia.br/desafios-da-educacao-profissional-e-tecnologica-novas-faces-dos-mesmos-problemas/>. Acesso em: 12 set. 2019.

CATTANI, A. D. Formação Profissional. In: CATTANI, A. D. Trabalho e Tecnologia: dicionário crítico. Petrópolis - RJ: Vozes; Porto Alegre: Ed. Universidade, 1997, p. 94-99.

\footnotetext{
${ }^{13}$ A esse respeito, sugerimos a leitura de Afonso e Gonzalez (2018).
} 
ENGELS, F. A situação da classe trabalhadora na Inglaterra. São Paulo: Boitempo, 2010.

MANACORDA, M. A. Marx e a pedagogia moderna. Campinas, SP: Editora Alínea, 2007.

MARX, K. Crítica ao Programa de Gotha. São Paulo: Boitempo, 2012.

. O Capital - Livro primeiro. São Paulo: Ed. Nova Cultural, 1996.

MOURA, D. H. Ensino médio e educação profissional no Brasil nos anos 2000: movimentos contraditórios. In: Dante Henrique Moura. (Org.). Produção de conhecimento, políticas públicas e formação docente em educação profissional. 1ed. Campinas - SP: Mercado de Letras, 2013, p. 141-200.

NOGUEIRA, M. A. Educação, saber, produção em Marx e Engels. São Paulo: Cortez, 1990.

SAVIANI, D. O trabalho como princípio educativo frente às novas tecnologias. In: FERRETI, C. J. /et al./ (org.). Novas tecnologias, trabalho e educação: um debate multidisciplinar. Petrópolis, RJ: Vozes, 1994.

Enviado em: 20 de setembro de 2019.

Avaliado em: 10 de outubro de 2019.

Inserido em: 10 de dezembro de 2019. 